\title{
Role of yoga in study of pulmonary function test in young healthy adults
}

\author{
Behera $M^{1}$, Priyadarsini $N^{2}$, Mohapara $D^{3}$, Mishra $T^{4}$, Behera $\mathrm{AA}^{5}$ \\ ${ }^{1}$ Dr Manasi Behera, Assistant Professor, Department of Physiology, ${ }^{2}$ Dr Nibedita Priyadarsini, Associate Professor, \\ Department of Physiology, ${ }^{3}$ Dr Dipti Mohapatra, Associate Professor, Department of Physiology, ${ }^{4}$ Dr Tapaswini Mishra, \\ Assistant Professor, Department of Physiology, ${ }^{5}$ Anugya Aparajita Behera. All are affiliated with IMS \& SUM Hospital, \\ Bhubaneswar, Odisha, India
}

Address for correspondence: Dr Manasi Behera Email: drmanasi18@gmail.com

\begin{abstract}
Introduction: Yoga has been reported to improve pulmonary function tests in healthy and respiratory illness. Aim: This study was done to find out the effects of yoga practice on pulmonary function tests. Materials and methods: This study was done on 50 subjects, (30 males, 20 females), with written consent. The subjects were the MBBS students of $1^{\text {st }}$ year with the age between $17-21$ years. The respiratory parameters like FVC, PEFR and MVV were determined in both groups using the instrument computerized Spirometer. Results: FVC, PEFR and MVV were found to be increased in both male and female subjects after practicing a short term yoga. Conclusion: From this study we concluded that yoga can be advised to improve respiratory efficiency in healthy as well as an alternative therapy in respiratory disorders.
\end{abstract}

Key words: Yoga, Pranayama, FVC, PEFR, MVV.

\section{Introduction}

Breathing sustains life. It clears the mind and calms all the emotions and releases the flow of energy in us. Yoga is a science practiced in India over thousands of years [1]. In recent times, medical fraternity is much attracted towards the effect of yoga. It includes asana, pranayama (controlled breathing) and proper relaxation. Yoga aims to treat illness by improving health on all levels. Yoga therapy is both preventive and curative. Some research studies report that many people with respiratory disorders had benefited by yoga. Yoga is considered as a good exercise for maintaining a healthy life style and also it has a great effect on the lung functions.

It is claimed that yogic practices help in prevention, control and rehabilitation of many respiratory diseases [2]. This study was done to test that short term yoga practices improve chest wall expansion as well as lung function tests in young healthy adults. Many studies are available showing the effect of yoga on pulmonary function tests in normal as well as in respiratory

Manuscript received 25 $5^{\text {th }}$ April 2016

Reviewed: $7^{\text {th }}$ May 2016

Author Corrected: $18^{\text {th }}$ May 2016

Accepted for Publication 29 May 2016 diseases. These studies were done for different duration of time. Actually benefits of yoga depend on duration of yoga practice. The current study was done for short term duration of yoga practice in healthy normal young adults to see the beneficial effects on pulmonary function tests.

\section{Materials and Methods}

The present study was conducted on undergraduate students of $1^{\text {st }}$ year MBBS, among which 30 subjects are boys and 20 subjects are girls.

Inclusion criteria- Age group- 17 - 21 years.

Exclusion criteria- Students were instructed not to do other exercises like athletics, gyms or sports trainings during study.

Collection of Data- All the students were informed about the nature of the study. A written consent was taken each of them. The data was collected which included age, sex, height and weight of the subject. The equipment used for pulmonary function test was 
computerized spirometer. The procedure was explained briefly to each subject. All the students were tested in sitting position. The pulmonary function test parameters like Forced Vital Capacity (FVC), Maximum Voluntary Ventilation (MVV) and Peak Expiratory Flow Rate (PEFR) were recorded. Pulmonary function tests were recorded by same instrument with proper demonstration. The subject was instructed to take deep inspiration followed by rapid and forceful expiration as possible in mouthpiece. During the recording all the subjects were instructed to use the nose clip. For each procedure 3 recordings done from which the best reading was taken. After recording the above parameters the subjects were trained to perform yoga exercise asans and pranayama for 30 minutes, 6 days per week period, all studied parameters were measured again with the same instrument and same instruction.
All the subjects performed the yoga postures (Asanas), Bhastrica Pranayamas, breathing exercises like Kapalbharti and Anuloma Viloma for 30 minutes a day, one time a day, 6 days a week until 6 weeks under expert s observation. Subjects were instructed not to practice any form of other exercise during study. Participants were allowed to do their routine activities during the study period.

Statistical Analysis: Statistical analysis was done by calculation of Mean and Standard Deviation (SD) and $\mathrm{p}$ value. All the data were expressed as Mean $+\mathrm{SD}$ and analyzed using $\mathrm{Z}$ test, separately for boys and girls. $\mathrm{P}$ values of less than 0.001 indicated a significant difference.

\section{Results}

The pulmonary function tests were carried out in 50 normal healthy students of $1^{\text {st }}$ year MBBS. Out of 50 students, 30 were boys and 20 were girls. The aim of the study was to see whether any changes occur in the lung parameters after the performance of yoga (asanas and pranayama). The students were from age group of 17-21 years. Following observations were noted.

Table No 1: Pulmonary function tests before and after performance of yoga in males $(\mathbf{n}=30)$.

\begin{tabular}{|l|l|l|l|}
\hline Parameter & Mean \pm SD $($ Before) & Mean \pm SD $($ After $)$ & p value \\
\hline FVC ( L ) & $2.71 \pm 0.207$ & $3.09 \pm 0.168$ & $<0.001$ \\
\hline PEFR ( L/Sec ) & $4.12 \pm 0.98$ & $5.43 \pm 1.11$ & $<0.001$ \\
\hline MVV ( L/min ) & $98.04 \pm 8.431$ & $105.13 \pm 8.507$ & $<0.001$ \\
\hline
\end{tabular}

The table - 1 shows, the lung function tests measured in male subjects before and after the practice of yoga. Here the yoga exercise significantly increased FVC, MVV and PEFR values $(\mathrm{p}<0.001)$.

Table No 2: Pulmonary function tests before and after performance of yoga in females (n=20).

\begin{tabular}{|l|l|l|l|}
\hline Parameter & Mean \pm SD $($ Before $)$ & Mean \pm SD $($ After $)$ & P value \\
\hline FVC $(\mathrm{L})$ & $2.52 \pm 0.104$ & $2.80 \pm 0.108$ & $<0.001$ \\
\hline PEFR $(\mathrm{L} / \mathrm{Sec})$ & $3.92 \pm 0.351$ & $4.92 \pm 1.253$ & $<0.001$ \\
\hline MVV $(\mathrm{L} / \mathrm{min})$ & $88.16 \pm 16.211$ & $98.04 \pm 18.231$ & $<0.001$ \\
\hline
\end{tabular}

The Table 2 represents pulmonary functions tests in female subjects before and after the practice of short term yoga. It shows significant increase in FVC, PEFR and MVV values ( $p$ value $<0.001$ ).

\section{Discussion}

Yoga is an ancient system, which brings harmony in body and mind. Bhagvad Gita states Yoga is skill in action. The present data indicates that 6 weeks yoga training improves respiratory functions especially the lung volumes and chest expansions. Mandanmohan et al observed significant improvement in lung parameters and skeletal muscle strength in Indian children [3]. Raub JA described the yoga training improving the muscle strength and flexibility [4]. L. N. Joshi et al found significant improvement in FVC, PEFR and MVV after 6 weeks pranayama practice [5]. Chhibber $\mathrm{R}$, Mondal S. et al observed significant increase in FVC, PEFR at $6^{\text {th }}$ and $12^{\text {th }}$ week of pranayama practice in healthy females [6]. A type of yoga, the asanas and pranayama involves effects like 1 - improvement in breathing 2 - calmness 3 - increased cardiovascular, 
digestive and endocrine functions ( Monro et al, 1997 ) [7] .

As shown in table 1 and 2, the lung function tests like FVC, PEFR and MVV show statistically significant improvement with regular practice of yoga.

These effects may be explained as: -

Yogic breathing raises the diaphragm at a higher level than its normal, helps in efficient movement of diaphragm improves its strength which improves vital capacity [8]. In Kapalbhati - there is full use of diaphragm and abdominal muscles of breathing. It helps in removal of secretions from bronchial tree, clearing up respiratory passages [8]. In Bhastrika pranayama, there is forceful and rapid breathing which exercises expiratory and inspiratory muscles [9]. During pranayama there is slow and prolonged inspiration as well as expiration. Due to this elastin and collagen fibres of lung parenchyma stretch which is a major physiological stimulus for release of lung surfactant into alveolar space, increasing the lung compliance [10]. Due to lung inflation, there occurs release of prostaglandins which decreases bronchial smooth muscle tone [11].

Ultimately yoga with its calming effect on the mind can reduce and release emotional stresses thereby withdrawing the broncho - constrictor effect [12]. Filling of lungs to maximum is caused by deep inspiration and breath holdings during pranayama are seen. Yoga postures cause isometric contraction, which increase skeletal muscle strength [13]. Pranayama and asanas remove the undue tension from the skeletal muscles helping the thorax to relax better, which in turn improves vital capacity [14]. Thus our study validates the physiological changes and improvement in pulmonary function tests by regular yoga practice of asanas and pranayama can increase the respiratory efficiency also.

\section{Conclusion}

This study of pulmonary function tests by practice of yoga concluded that there occurs significant improvement in respiratory efficiency in healthy individuals and hence to prevent respiratory disorders in future. Regular practice of short term yoga improves respiratory breathing capacity by increasing chest wall expansion. Further studies are to be undertaken with large sample size and for varied age groups to know the effect of yoga to population in general.
Funding: Nil, Conflict of interest: None initiated. Permission from IRB: Yes

\section{References}

1. Gilbert C. Yoga and bteathing. J bodywork Mov Ther.1999; 3: 44-54.

2. Dr Vinayak P Doijad, Dr Anil. D. Surdi, Effect of short term yoga practice on pulmonary function tests. Indian Journal of Basic and Applied Medical Research.2012; 3(1): 226-30.

3. Mandanmohan, Jatiya L, Udapa K, and Bhavanani AB. Effect of yoga training on handgrip, respiratory pressure and pulmonary function. Indian $\mathrm{J}$ Physiol Pharmacol. 2003; 47(2):387-92

4. Raub JA. Psychophysiologic effects of Hatha yoga on musculoskeletal and cardiopulmonary function, a literature review. J Altern Compl Med.2002; 8: 797812 .

5. L. N. Joshi.Effect of short term pranayama practice on breathing rate and ventilatory functions of lung.Indian J Physiol Pharmacol.1992; 36(2): 105-108.

6. Chhiber R. Mondal S. et al. Comparative study on effect of pranayama and meditation on pulmonary function in healthy females.Indian J. Physiol Pharmacol. 2006; 52(5): 161.

7. Monro R.Yoga therapy. J Bodywork Mov Ther.1997; 1: $215-18$.

8. Makwana K. Effects of yogic exercises on human physical efficiency. IndianJournal.Med. 1975; 63(4): 1369-1376.

9. Madan Mohan et al. Effect of yoga training on reaction time, respiratory endurance and muscle strength. Indian J. Physiol Pharmacol. 1992; 36(4): 229233.

10. Iyengar B. K. S .Light on yoga.Geovge Allan and Unwin Ltd. London.1968; 243-45.

11. Hildebran J.N. Groke, Clements JA. Surfactant release in exercised rat lung is stimulated by air inflation. J. Appli. Physiol.1981;51: 905-10. 
12. Yadav Raj Kumar and Das Shobha.Effect of yogic practices on pulmonary functions inyoung females. Indian J Physiol Pharmacol. 2001; 45(4): 493-96.

13. Gopal KS, Bhatnagar OP, Subramanian N, Nishith SD. Effect of yogasans and pranayamas on blood pressure, pulse rate and respiratory functions. Indian J Physiol Pharmacol.1973; 17: 273-76.

14. Makwana K, Khirwwadkar N, Gupta HC.Effect of short term yogapractice on ventilatory function tests.Indian J Physiol Pharmacol.1988;32: 202-08.

\section{How to cite this article?}

Behera M, Priyadarsini N, Mohapara D, Mishra T, Behera AA. Role of yoga in study of pulmonary function test in young healthy adults. Int J Med Res Rev 2016;4(6):872-875doi: 10.17511/ijmrr.2016.i06.02. 